\title{
Fundamentos humanísticos na formação de estudantes de medicina: estudo de caso
}

\author{
Humanist foundations in the training of students of \\ medicine: case study
}

\author{
Luiz Alberto Queiroz', Nara Lima Alexandre ${ }^{2}$ \\ 'Autor para correspondência. Escola Bahiana de Medicina e Saude Publica - EBMSP, Salvador, Bahia - Brasil. b.fernandez@ig.com.br
} ${ }^{2}$ Escola Bahiana de Medicina e Saude Publica - EBMSP, Salvador, Bahia - Brasil. naraalexandre@uol.com.br

RESUMO | INTRODUÇÃO: A medicina vem conquistando alto poder tecnológico, imprescindível para muitos diagnósticos e tratamentos atuais. Por outro lado, observa-se o distanciamento do médico do que deve ser seu instrumento de trabalho: a pessoa. A Escola Bahiana de Medicina vem implementando ações que visam integrar o estudante aos elementos subjetivos da prática médica, através de matérias como a Psicodinâmica da Clínica Médica. OBJETIVOS: Retratar a realidade do ensino da disciplina Psicodinâmica na Escola Bahiana de Medicina e Saúde Pública; avaliar o desempenho da matéria Psicodinâmica, ministrada no $7^{\circ}$ semestre do curso de medicina, bem como a necessidade do ensino de fundamentos humanísticos perante a comunidade discente dessa escola. MÉTODOS: Estudo de caso realizado através de análise documental, entrevista com professor da matéria e aplicação de questionário. Após aprovação do Comitê de ética, aplicaram-se questionários contendo sexo, idade, ano do curso, perguntas referentes aos assuntos desenvolvidos na matéria tais quais relação médico-paciente, morte e morrer, vocação médica e humanização etc. RESULTADOS: O objetivo da psicodinâmica é propiciar uma visão integral do paciente. Quanto aos questionários, foram respondidos por 124 alunos distribuídos entre as $4^{a}, 5^{a}$ e $6^{a}$ séries. $88,7 \%$ concordam que a matéria forneceu bases para estabelecer uma relação médico-paciente eficaz. $91,2 \%$ concordam que a matéria chamou atenção para o aspecto terapêutico que pode ter a relação médico-paciente. $99,2 \%$ concordam que para atender com humanidade é preciso primeiro, humanizar-se. $71 \%$ dos alunos concordam que a matéria ajudou a diminuir a angústia e a culpa por não poder curar todos seus pacientes. $86,3 \%$ dos alunos concordam com a necessidade do ensino de fundamentos humanísticos durante todo o curso. CONCLUSÕES: A Psicodinâmica da Clínica médica vem atingindo os objetivos propostos. Há necessidade do ensino de fundamentos humanísticos durante todo curso de medicina.

PALAVRAS-CHAVE: Humanização da assistência. Educação médica. Estudantes de medicina.

\begin{abstract}
I BACKGROUND: Medicine has been gaining high technological power, essential for many diagnoses and current treatments. On the other hand, one observes the distancing of the physician from what should be his instrument of work: the person. Bahiana School of Medicine has been implementing actions aimed at integrating the student into the subjective elements of medical practice through such subjects as the Psychodynamics of the Medical Clinic. OBJECTIVES: To portray the reality of the teaching of the discipline Psychodynamics in the Bahiana School of Medicine and Public Health; to evaluate the performance of the psychodynamic material taught in the 7th semester of the medical course, as well as the need to teach humanistic fundamentals to the student community of this school. METHODS: Case study conducted through documentary analysis, interview with professor of the subject and application of questionnaire. After approval by the Ethics Committee, questionnaires containing sex, age, year of the course, questions related to the subjects developed in the subject were applied, such as doctor-patient relationship, death and dying, medical vocation and humanization etc. RESULTS: The goal of psychodynamics is to provide an integral view of the patient. The questionnaires were answered by 124 students distributed between the 4 th, 5 th and 6 th grades. $88.7 \%$ agreed that the subject provided grounds for establishing an effective physician-patient relationship. $91.2 \%$ agreed that the subject drew attention to the therapeutic aspect that can have the doctor-patient relationship. $99.2 \%$ agree that in order to meet humanity, it is first necessary to humanize. $86.3 \%$ of the students agree on the need to teach humanistic fundamentals throughout the course. CONCLUSIONS: A Psicodinâmica da Clínica médica vem atingindo os objetivos propostos. Há necessidade do ensino de fundamentos humanísticos durante todo curso de medicina.
\end{abstract}

KEYWORDS: Humanization of assistance. Medical education. Medical students. 


\section{Introdução}

A medicina pode ser definida como uma modalidade de trabalho social instituída como profissão de serviço e uma instituição social a serviço da humanidade. ${ }^{\prime}$ Outra definição é que medicina é uma atividade humana exercida por seres humanos em seres humanos. ${ }^{2: 897}$ Compreende-se então, a importância do ensino de fundamentos humanísticos para estudantes de medicina.

Ao longo da história, a medicina vem sofrendo profundas transformações, chegando ao século XXI, com conquistas inimagináveis e um grande poder de diagnóstico e tratamento das doenças. Apesar dos avanços inegáveis da medicina como ciência, aspectos relacionados com a humanização, relação médico-paciente, a morte e o morrer, entre outros, vem sendo deixados de lado. Atualmente, o paradigma que prevalece na medicina ocidental contemporânea privilegia os aspectos objetiváveis que são traduzidos como doença e deixa de lado o universo subjetivo do sofrimento. $3: 10$

Isso se deveu em grande parte ao seguimento, pelas escolas médicas, ao relatório Flexner, datado de 1912, que fundamentou o ensino da medicina com uma visão biocêntrica/tecnocêntrica. Segundo Pessini ${ }^{4}$, doutor em teologia moral, as escolas médicas após seguirem o relatório Flexner, passaram a formar estudiosos em doenças, principalmente especialistas, que atuassem em hospitais, resultando num modelo reducionista, que não privilegia a visão da pessoa como um todo. Foi um período em que o campo científico se opôs a humanização, com perda do pensamento de integralidade. ${ }^{5}$

Esse tipo de ensino e prática trouxe um enorme prejuízo à atuação médica, afastando-o do que deve ser seu objeto de trabalho, a pessoa. Com isso, a atuação médica vem sendo questionada e reformulada desde a metade do século passado. Nos anos 50, 0 filósofo e médico alemão Karl Jaspers desenvolveu uma série de reflexões sobre o médico na idade da técnica e uma crítica muito forte à psicanálise. Ele enfatizava a necessidade da medicina recuperar os elementos subjetivos da comunicação entre o médico e o paciente, assumidos impropriamente pela psicanálise e esquecidos pela medicina, perseguindo um caminho baseado exclusivamente na instrumentação técnica e na objetividade dos dados. ${ }^{6: 648}$

Os avanços científicos na área médica contribuem para a maior expectativa de vida que temos atualmente e para a melhoria da saúde de milhares de pessoas, paradoxalmente, nunca tantas dúvidas pairaram sobre a medicina e sobre os médicos, que nunca foram tão desaprovados como nos dias de hoje $e^{7}$.

Nesse contexto, as escolas médicas têm uma grande responsabilidade: precisam capacitar seu aluno, desenvolvendo um currículo que contemple os conhecimentos técnicos necessários, bem como os saberes humanísticos, lembrando que as atuais Diretrizes Curriculares Nacionais para o curso de medicina, estabelecem que a estrutura do curso de medicina deve incluir dimensões éticas e humanísticas, desenvolvendo no aluno atitudes e valores orientados para a cidadania. ${ }^{8,9}$

Por tudo isso, as faculdades de medicina têm tentado se adaptar a essa nova realidade, abrindo espaços para que o estudante conheça e discuta essas transformações, podendo formar bases que possam lhe ajudar a refletir sobre que tipo de médico a sociedade está necessitando e exigindo, e que tipo de médico ele quer ser.

Diante dessa realidade, a Escola Bahiana de Medicina e Saúde Pública contempla em sua grade curricular matérias que privilegiam o ensino e a prática da Psicologia Médica. Essas matérias, como Psicologia Médica, Desenvolvimento dos Ciclos da Vida, Saúde Comunitária, Saúde da Família e Psicodinâmica da Clínica Médica, visam alertar os alunos da importância da valorização da pessoa dentro do processo saúde-doença.

\section{Objetivo primário}

Avaliar o desempenho e a aceitação, perante os discentes, da matéria Psicodinâmica da Clínica Médica no curso de medicina da Escola Bahiana de Medicina e Saúde Pública. 


\section{Objetivos secundários}

- Fazer um histórico da implantação e desenvolvimento da matéria Pscodinâmica da Clínica Médica.

- Avaliar a sensibilidade dos alunos para os tópicos desenvolvidos na matéria Psicodinâmica da Clínica Médica.

- Identificar possíveis diferenças entre os grupos dos $4^{\circ}, 5^{\circ}$ e $6^{\circ}$ anos, quanto às suas opiniões sobre a Psicodinâmica da Clínica Médica.

- Conhecer a necessidade do ensino de fundamentos humanísticos perante a comunidade discente da Escola Bahiana de Medicina e Saúde Pública.

\section{Materiais e métodos}

\section{Caracterização do Estudo}

Trata-se de um estudo de caso, desenvolvido através de análise documental e entrevista com o professor responsável pela matéria Psicodinâmica da Clínica Médica, somado a dados epidemiológicos, construídos por meio de levantamento de dados em campo e posterior análise.

\section{Amostra}

A amostra é composta por 124 estudantes dos $4^{\circ}$, $5^{\circ}$ e $6^{\circ}$ anos do curso de medicina da Escola Bahiana de Medicina e Saúde Pública, de uma população total de 600 estudantes, que cursam as referidas séries.

\section{Procedimento para coleta de dados}

O projeto foi encaminhado ao Comitê de Ética em Pesquisa da Escola Bahiana de Medicina e Saúde Pública e aprovado segundo protocolo 1 20/2008.

A coleta de dados teve início em novembro de 2008 e foi completada em abril de 2009.

Foi feita entrevista com $\circ$ professor responsável onde foram conseguidas informações sobre a implantação da matéria, somando-se a isso foi feita análise da ementa conhecendo-se os objetivos e me- todologia da Psicodinâmica da Clínica Médica.

As informações provenientes dos alunos, foram obtidas através de questionários semi-estruturados contendo 14 questões, aplicados pela autora. Não houve necessidade de treinamento prévio da entrevistadora, tal como estudo piloto.

O questionário foi dividido em informações sócio-demográficas, ano de matrícula no curso e informações sobre assuntos pertinentes a matéria Psicodinâmica da Clínica Médica tais quais: relação médico-paciente, humanização e morte e morrer. Os questionamentos sobre a matéria foram respondidos através da escolha de uma das opções oferecidas: concordo totalmente, concordo parcialmente, indiferente, não concordo e não concordo definitivamente, com exceção das questões 4 e 12 .

Os objetivos da pesquisa foram apresentados aos estudantes e foi solicitado o consentimento assinado de participação no estudo, após conhecimento dos objetivos do estudo e do tipo de informação que seria solicitada. Foi assegurado o sigilo das informações levantadas, sendo que apenas dados consolidados foram analisados e divulgados, impossibilitando a identificação dos indivíduos pesquisados.

\section{Análise de dados}

Foi utilizado o programa SPSS versão 14.0, para estruturação do banco de dados. Os resultados obtidos no estudo foram expressos por frequiências e percentuais e ilustrados por gráficos e tabelas.

\section{Resultados}

\section{Entrevista e anàlise documental}

Desde o ano de 2002, com a inauguração do $A D A B$, Ambulatório Docente Assistencial de Brotas da Escola Bahiana de Medicina e Saúde Pública, surgiu através do então chefe da cadeira de clínica médica, Dr. Ricardo Sinai Neves, a proposta para que o professor Luiz Queiroz aproveitasse um espaço de tempo na grade curricular, para trabalhar o sofrimento de quem cuida. Iniciou-se então o ciclo da Psicodinâmica da Clínica Médica, como foi denomi- 
nada pelo professor da matéria, Luiz Alberto Cravo Pinto de Queiroz.

A Psicodinâmica da Clínica Médica, como consta em seu plano de ensino, é um módulo integrado ao estágio de Clínica Médica do $4^{\circ}$ ano do curso de medicina, com carga horária de 16 horas, dividida em 6 encontros, 1 vez por semana, com um grupo de no máximo 34 alunos. É uma atividade obrigatória. Podendo haver reprovação, caso não alcance a média requerida pela faculdade. $O$ trabalho se desenvolve de forma participativa, a partir de aulas expositivas/vivenciais, dinâmicas de grupo e apresentação de caso clinico, além da realização de portfólio.

Faz parte desde 2005, do Núcleo de Saúde Mental e Neurologia. Tem como sua ementa: estudar - processo individual de crescimento do estudante de medicina ao atuar como cuidador, trabalhar as angústias, necessidades e dificuldades pessoais enfrentadas e vivenciadas pelos estudantes, a partir de fundamentos teóricos e vivenciais do Ser Médico.

O objetivo geral deste módulo é propiciar uma visão integral do paciente, situando o ritual semiológico médico do ouvir, do olhar e do tocar, considerando o funcionamento mental do paciente e do médico e de todos aqueles que se ocupam da função de cuidador. E os objetivos específicos são: exercitar o diálogo com os pacientes a fim de estabelecer condições para a relação médico-paciente; conhecer os fatores pessoais, familiares e ambientais relacionados ao paciente; aprender sobre o aspecto terapêutico da relação médico-paciente; compreender como os conflitos psíquicos poderão ser expressos por um sentimento de alteração da saúde física ou se fixar em uma perturbação psíquica; desenvolver a capacidade de incluir a Semiologia Mental no Raciocínio Clínico; refletir sobre subjetividade do médico expressa na interação com o paciente e no trabalho com a equipe multidisciplinar considerando suas possíveis dificuldades; considerar a importância de trabalhar as questões emocionais do médico; considerar a escolha profissional frente à realidade vivenciada na pratica médica e refletir sobre o trabalho com a equipe multidisciplinar.

Habilidades como estabelecimento efetivo da relação médico-paciente, compreensão da subjetivida- de no processo do adoecer e atuar dentro do processo de humanização, estão sendo cada vez mais exigidas para o médico. Além disso, é preciso estar preparado emocionalmente para lidar com o sofrimento pessoal, inerente à medicina. Nesse sentido, justifica-se a importância de avaliar como a matéria Psicodinâmica da Clínica Médica, vem interferindo na vida de estudantes de medicina, no intuito de desenvolver tais habilidades.

\section{Questionários}

Fizeram parte da amostra 124 estudantes de medicina da Escola Bahiana de Medicina e Saúde Pública, com idade variando de 20 a 39 anos e uma média de 23,46 anos (Figura 1).

Quanto a variável sexo, 77 estudantes eram do sexo feminino e 47 do masculino. Houve um predomínio maior de mulheres nas turmas do $4^{\circ}$ e $6^{\circ}$ anos. As entrevistas foram feitas de forma aleatória, dando ênfase ao ano do curso e não ao sexo. Os alunos estavam distribuídos da seguinte forma, quanto ao ano de matrícula: 43 cursavam $\circ 4^{\circ}$ ano, $41 \circ 5^{\circ}$ ano e $40,06^{\circ}$ ano. As distribuições por sexo e ano de matrícula encontram-se na Tabela 1.

Figura 1. Distribuição da amostra por idade

Distribuição por idade

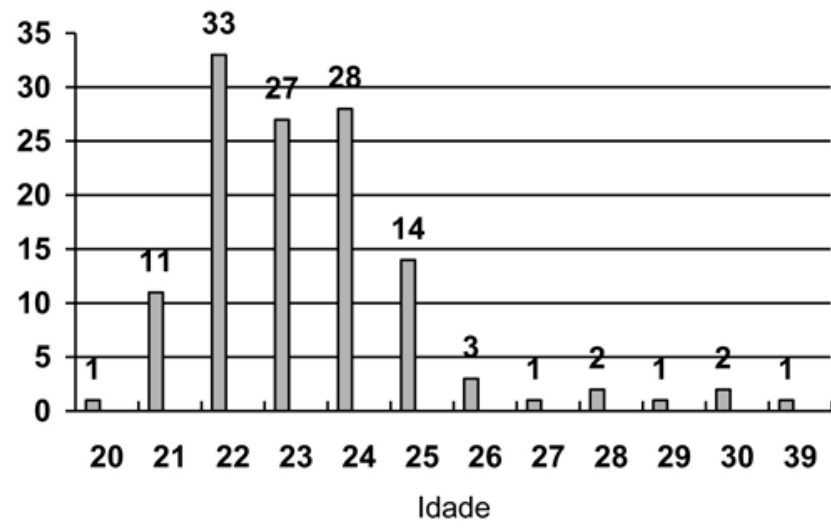

Tabela 1. Distribuição da amostra por sexo e ano de matrícula.

\begin{tabular}{|c|c|c|c|c|c|c|}
\hline \multirow[b]{2}{*}{$\underline{\text { Sexo }}$} & \multicolumn{2}{|c|}{ Ano 4} & \multicolumn{2}{|c|}{ Ano 5} & \multicolumn{2}{|c|}{ Ano 6} \\
\hline & $\mathrm{N}$ & $\%$ & $\mathrm{~N}$ & $\%$ & $\mathrm{~N}$ & $\%$ \\
\hline Masculino & 15 & 34,9 & 20 & 48,9 & 12 & 30 \\
\hline Feminino & 28 & 65,1 & 21 & 51,1 & 28 & 70 \\
\hline Total & 43 & 100 & 41 & 100 & 40 & 100 \\
\hline
\end{tabular}


A tabela 2 mostra que a maioria dos alunos, independente do ano que cursam, concordam com as questões que thes foram feitas sobre a matéria. As questões foram adaptadas e transcritas para a tabela 2, exceto as questões 4 e 12, e mostra também a distribuição de frequência simples das respostas ao questionário. As respostas "concordo parcialmente" e "concordo totalmente" foram agrupadas na coluna concordo, bem como "não concordo definitivamente" e "não concordo" foram agrupadas na coluna discordo.

Tabela 2. Distribuição de frequências simples do questionário.

\begin{tabular}{|c|c|c|c|}
\hline \multirow[b]{2}{*}{ Questão } & \multicolumn{3}{|c|}{ Resposta } \\
\hline & Discordo & \multirow{2}{*}{$\begin{array}{l}\text { Indiferente } \\
N(\%)\end{array}$} & \multirow{2}{*}{$\begin{array}{l}\text { Concordo } \\
N(\%) \\
\end{array}$} \\
\hline & $N(\%)$ & & \\
\hline $\begin{array}{l}\text { 1.A matéria forneceu bases para estabelecer uma } \\
\text { relação médico paciente eficaz? }\end{array}$ & $6(4,8)$ & $8(6,5)$ & $110(88,7)$ \\
\hline $\begin{array}{l}\text { 2.Passou a dar mais atenção aos fatores pessoais, } \\
\text { familiares e ambientais relacionados ao paciente? }\end{array}$ & $7(5,6)$ & $16(12,9)$ & $101(81,4)$ \\
\hline $\begin{array}{l}\text { 3.A matéria chamou atenção para o aspecto } \\
\text { terapêutico que pode ter relação médico- paciente? }\end{array}$ & $2(1,6)$ & $9(7,3)$ & $113(91,2)$ \\
\hline $\begin{array}{l}\text { 5.A matéria the ajudou a refletir sobre sua escolha por } \\
\text { medicina? }\end{array}$ & $13(10,5)$ & $44(35,5)$ & $67(54,1)$ \\
\hline $\begin{array}{l}\text { 6.Para atender com humanidade é preciso primeiro, } \\
\text { trabalhar em si a humanização? }\end{array}$ & $0(0)$ & $1(0,8)$ & $123(99,2)$ \\
\hline 7.A matéria mudou sua visão sobre humanização? & $15(12,1)$ & $27(21,8)$ & $82(66,2)$ \\
\hline $\begin{array}{l}\text { 8.A matéria lhe ajudou a diminuir a angústia e a culpa } \\
\text { por não poder curar boa parte dos seus pacientes? }\end{array}$ & $10(8,0)$ & $26(21,0)$ & $88(71,0)$ \\
\hline $\begin{array}{l}\text { 9. Você concorda com: o compromisso do médico é de } \\
\text { cuidar e não de curar? }\end{array}$ & $9(7,0)$ & $2(1,6)$ & $113(91,1)$ \\
\hline $\begin{array}{l}\text { 10.Os conhecimentos adquiridos com a matéria são } \\
\text { aplicáveis em sua vida profissional? }\end{array}$ & $2(1,6)$ & $1(0,8)$ & $101(97,6)$ \\
\hline 11.A matéria teve um impacto positivo na sua vida? & $2(1,6)$ & $7(5,6)$ & $115(92,8)$ \\
\hline $\begin{array}{l}\text { 13.A matéria conseguiu propiciar uma visão integral do } \\
\text { paciente? }\end{array}$ & $7(5,6)$ & $6(4,8)$ & $111(89,5)$ \\
\hline $\begin{array}{l}\text { 14.É necessário que esse tipo de aula seja disponivel } \\
\text { durante todo curso de medicina? }\end{array}$ & $11(8,9)$ & $6(4,8)$ & $107(86,3)$ \\
\hline
\end{tabular}

Alguns dados chamam atenção na tabela 2. Por exemplo, 99,2\% dos alunos concordaram com: para atender com humanidade é preciso primeiramente trabalhar em si a humanização (questão 6). Observa-se ainda que, $12,1 \%$ dos alunos discordaram quando perguntados se a matéria mudou sua visão sobre humanização. Já o maior número de respostas "indiferente" (35,5\%), foi dado a questão 5: A matéria the Ajudou a refletir sobre sua escolha por medicina?

As respostas das questões 4 e 12 apresentaram opções diferentes de escolha de respostas, sendo agrupadas de acordo com as figuras 2 a 5 . Observando as figuras 2 e 3 , se somarmos a quantidade de alunos que respondeu "me ajudou de alguma forma", "me ajudou de maneira significativa" e "me ajudou de maneira muito significativa", podemos perceber que 109 alunos $(87,9 \%)$ responderam que a matéria os ajudou a entender melhor a morte e o morrer.

Quanto a questão 12 (Figuras 4 e 5), que indaga sobre a matéria ter mudado a maneira do aluno enxergar a medicina, a maioria , $74(59,68 \%)$ alunos, responderam que tiveram uma mudança positiva após a matéria, $46(37,1 \%)$ se mostraram indiferentes e $2(1,61 \%)$ alunos responderam que a matéria os fez ver que medicina não é sua vocação. 
Figura 2. Frequência simples das respostas dadas à questão 4.(N, não me ajudou em nada; $A F$, me ajudou de alguma forma; $S$, me ajudou de maneira significativa; $M S$, me ajudou de maneira muito significativa.

4.A matéria ajudou a entender a morte e o morrer?

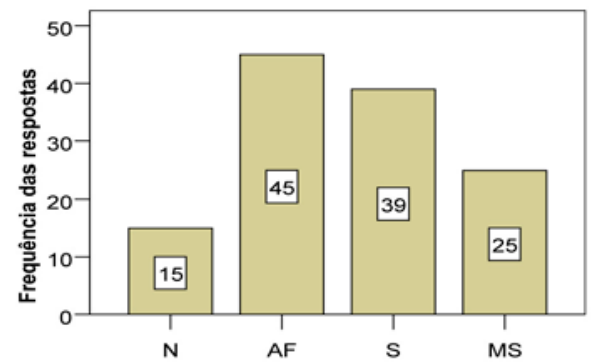

Figura 4. Frequência simples das respostas dadas à questão 12.(MP, mudança positiva; $M N$, mudança negativa; I, indiferente; $N V$, a matéria me fez ver que medicina não é minha vocação.

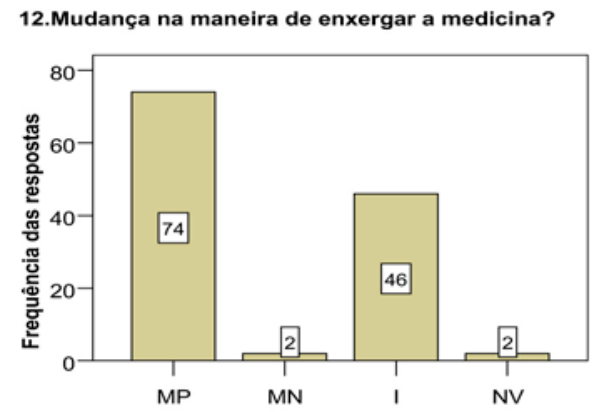

A tabela 3 mostra a frequência de respostas de acordo com $\circ$ ano de matrícula no curso de medicina. Para análise estatística, as respostas "não concordo definitivamente" e "não concordo" foram agrupadas, bem como as respostas "concordo parcialmente" e "concordo totalmente" . O teste de qui quadrado foi utilizado para avaliar correlação entre as variáveis qualitativas. Foi considerado estatisticamente significativo o valor de $p<0,05$. Quando perguntados se a matéria forneceu bases para estabelecer uma relação médico-paciente eficaz, questão 1, mais de $80 \%$ dos alunos de cada ano concordaram, destacando-se os alunos do $6^{\circ}$ ano, dos quais houve uma concordância entre $97,5 \%$ dos
Figura 3. Percentagem das respostas dadas à questão 4.(N, não me ajudou em nada; $A F$, me ajudou de alguma forma; $S$, me ajudou de maneira significativa; $M S$, me ajudou de maneira muito significativa.)

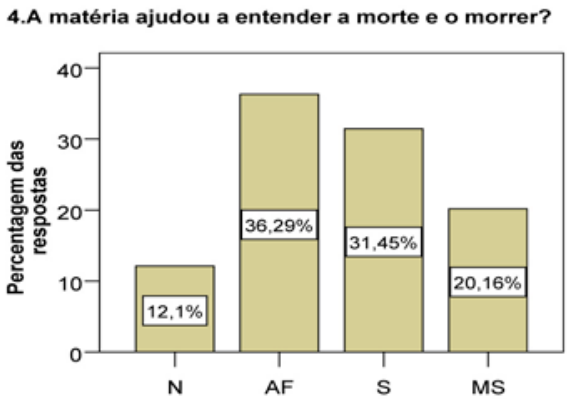

Figura 5. Percentagem das respostas dadas à questão 12.(MP, mudança positiva; $M N$, mudança negativa; I, indiferente; NV, a matéria me fez ver que medicina não é minha vocação

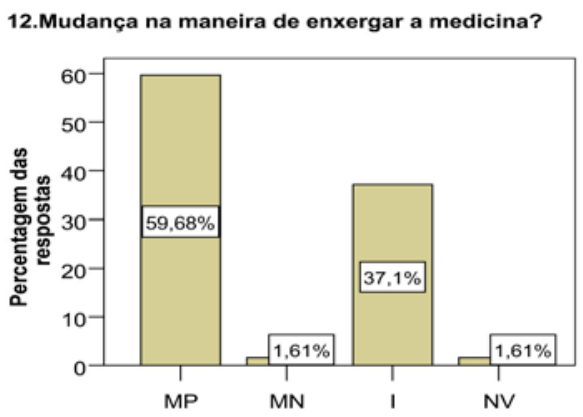

alunos. Houve significância estatística, valor de $\mathrm{p}$ igual a 0,047 , quando relacionado $o$ ano do curso com a pergunta 3 do questionário, que indaga se após a matéria os alunos prestaram mais atenção ao aspecto terapêutico que pode ter a relação médico-paciente. Sendo assim, $4,8 \%$ dos alunos do $5^{\circ}$ ano discordaram, 14,6 foram indiferentes e $80,5 \%$ concordaram, enquanto $97,7 \%$ dos alunos do $4^{\circ}$ ano e $95 \%$ dos alunos do $6^{\circ}$ ano concordaram. A questão 5 , que indaga se a matéria ajudou a refletir sobre a escolha dos alunos por medicina foi a que apresentou maior número de alunos discordando ou sendo indiferentes de acordo com o ano, mostrando $40 \%$ dos alunos do $6^{\circ}$ ano sendo indiferentes. 
Tabela 3. Distribuição de freqüências simples das respostas do questionário por ano do curso. (Q- Questão; $D$, discordo; I, indiferente; $C$, concordo; 1 , bases para estabelecer relação médico-paciente; 2-passou a dar mais atenção a fatores pessoais, familiares e ambientais; 3 - prestou mais atenção ao aspecto terapêutico da relação médico-paciente; 5- reflexão da escolha por medicina; 6- é preciso humanizar-se para atender com humanidade; 7-mudança na visão sobre humanização; 8 , houve redução da angústia por não poder curar boa parte dos pacientes; 9- o compromisso do médico é de cuidar, não de curar; 10 -os conhecimentos adquiridos são aplicáveis; 11 - a matéria teve impacto positivo; 13 - a matéria propiciou uma visão integral do paciente; 14 - são necessárias aulas como estas durante todo curso de medicina)

\begin{tabular}{|c|c|c|c|c|c|c|c|c|c|c|}
\hline \multicolumn{10}{|c|}{ Respostas } & \multirow{4}{*}{$\begin{array}{c}p \\
\text { valor }\end{array}$} \\
\hline \multirow{3}{*}{ Q } & & $4^{\circ}$ ano 1 & N-43 & & $5^{\circ}$ ano $\mathrm{N}$ - & & & $6^{\circ}$ ano & $N-40$ & \\
\hline & D & 1 & C & D & 1 & c & D & 1 & c & \\
\hline & $N(\%)$ & $N(\%)$ & $N(\%)$ & $N(\%)$ & $N(\%)$ & $N(\%)$ & $N(\%)$ & $N(\%)$ & $N(\%)$ & \\
\hline 1 & $3(7)$ & $4(9,3)$ & $36(83,7)$ & $3(7,3)$ & $3(7,3)$ & $35(85,4)$ & $0(0)$ & $1(2,5)$ & $39(97,5)$ & 0,085 \\
\hline 2 & $2(4,7)$ & $10(23,2)$ & $31(72,1)$ & $3(7,3)$ & $4(9,8)$ & $34(82,9)$ & $2(5)$ & $2(5)$ & $36(90)$ & 0,138 \\
\hline 3 & $0(0)$ & $1(2,3)$ & $42(97,7)$ & $2(4,8)$ & $6(14,6)$ & $33(80,5)$ & $0(0)$ & $2(5)$ & $38(95)$ & 0,047 \\
\hline 5 & $2(4,6)$ & $17(39,5)$ & $24(55,9)$ & $7(17,1)$ & $11(26,8)$ & $23(56,1)$ & $4(10)$ & $16(40)$ & $20(50)$ & 0,334 \\
\hline 6 & $O(0)$ & $O(0)$ & $43(100)$ & $O(0)$ & $O(0)$ & $41(100)$ & $0(0)$ & $1(2,5)$ & $39(97,5)$ & 0,347 \\
\hline 7 & $7(16,3)$ & $9(24,4)$ & $27(62,8)$ & $7(17,1)$ & $10(24,4)$ & $24(58,6)$ & $1(2,5)$ & $8(20)$ & $31(77,5)$ & 0,205 \\
\hline 8 & $3(7)$ & $9(20,9)$ & $31(72,1)$ & $4(9,8)$ & $10(24,4)$ & $27(65,9)$ & $3(7,5)$ & $7(17,5)$ & $30(75)$ & 0,816 \\
\hline 9 & $5(11,7)$ & $1(2,3)$ & $37(86)$ & $3(7,3)$ & $O(0)$ & $38(92,6)$ & $1(2,5)$ & $1(2,5)$ & $38(95)$ & 0,467 \\
\hline 10 & $1(2,3)$ & $O(0)$ & $42(97,7)$ & $1(2,4)$ & $1(2,4)$ & $39(95,1)$ & $0(0)$ & $O(0)$ & $40(100)$ & 0,553 \\
\hline 11 & $1(2,3)$ & $2(4,7)$ & $40(93)$, & $1(2,4)$ & $3(7,3)$ & $37(90,2)$ & $0(0)$ & $2(5)$, & $38(95)$ & 0,859 \\
\hline 13 & $2(4,7)$ & $1(2,3)$ & $40(93,1)$ & $5(12,8)$ & $4(9,8)$ & $32(78)$ & $0(0)$ & $1(2,5)$ & $39(97,5)$ & 0,051 \\
\hline 14 & $3(9,3)$ & $2(4,7)$ & $37(86)$ & $6(14,6)$ & $3(7,3)$ & $32(78)$ & $1(2,5)$ & $1(2,5)$ & $38(95)$ & 0,285 \\
\hline
\end{tabular}

O maior índice de concordância foi encontrado na questão 6, que pergunta se é preciso primeiro humanizar-se para atender com humanidade, em que $100 \%$ dos alunos dos $4^{\circ}$ e $5^{\circ}$ anos concordaram, bem como $97,5 \%$ dos alunos do $6^{\circ}$ ano. Quando perguntados se há necessidade de que matérias como essa sejam oferecidas, durante todo curso de medicina, questão 14 , os alunos do $6^{\circ}$ ano foram mais concordantes, com $95 \%$ das respostas referindo essa necessidade. Enquanto nos outros anos, essa percentagem foi de $86 \%$ entre os alunos do $4^{\circ}$ ano e $78 \%$ entre os alunos do $5^{\circ}$ ano.

As questões 4 e 12 foram analisadas separadamente, de acordo com o ano de matrícula. Em relação a questão $4,81,3 \%$ dos alunos do $4^{\circ}$ ano, $87,8 \%$ dos alunos do $5^{\circ}$ ano e $95 \%$ dos alunos do $6^{\circ}$ ano responderam que a matéria os ajudou a entender melhor a morte e o morrer (Figura 6). Quando perguntados se a matéria trouxe mudanças na maneira de enxergar a medicina, a maioria dos alunos, $25(58,1 \%)$ do $4^{\circ}$ e $30(75 \%)$ do $6^{\circ}$ ano, responderam que houve mudança positiva. Já a maioria dos alunos do $5^{\circ}$ ano, num total de $21(51,2 \%)$, responderam que eram indiferentes(Figura 7)

Figura 6. Frequência das respostas a questão 4 de acordo com $\circ$ ano. $p$ valor $=0,056$. ( $N$, não me ajudou em nada; $A F$, ajudou de alguma forma; $S$, ajudou significativamente; MS, ajudou muito significativamente)

4.A matéria ajudou a entender a morte e o morrer?

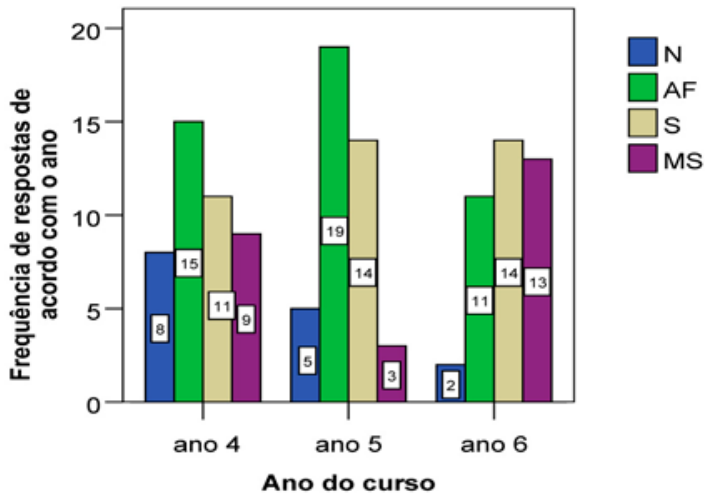

Figura 7. Frequência das respostas a questão 12 de acordo com o ano. $p$ valor = 0,059. (MP,mudança positiva; $M N$, maneira negativa;l, indiferente; NV, a matéria me fez ver que medicina não é minha vocação)

12.Mudança na maneira de enxergar a medicina?

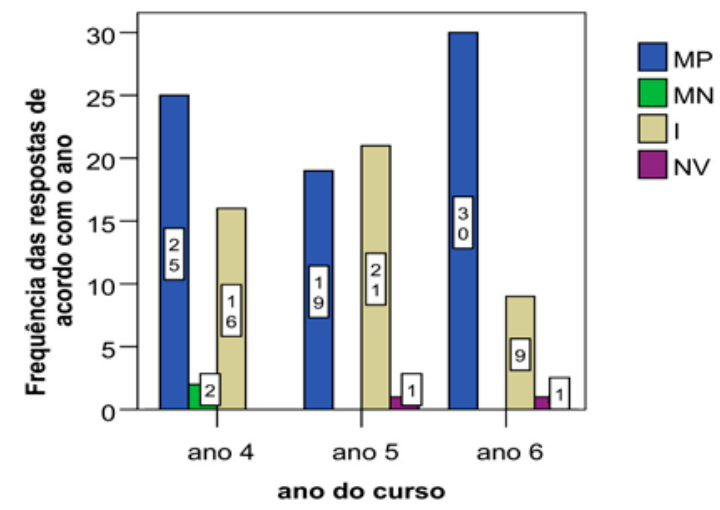


A tabela 4 mostra a distribuição de freqüências simples das respostas ao questionário de acordo com o sexo. A análise estatística mostra que não houve diferença estatística, quando comparadas essas duas variáveis, porém observa-se que no geral, os homens concordam mais que as mulheres com as questões que lhes foram feitas.

Tabela 4. Distribuição de freqüências simples das respostas do questionário de acordo com o sexo. (Q- Questão; D, discordo; l, indiferente; C, concordo; 1, bases para estabelecer relação médico-paciente; 2-passou a dar mais atenção a fatores pessoais, familiares e ambientais;3- prestou mais atenção ao aspecto terapêutico da relação médico-paciente; 5- reflexão da escolha por medicina; 6- é preciso humanizar-se para atender com humanidade; 7- mudança na visão sobre humanização; 8 , houve redução da angústia por não poder curar boa parte dos pacientes; 9- o compromisso do médico é de cuidar, não de curar; 10 -os conhecimentos adquiridos são aplicáveis; 11 - a matéria teve impacto positivo; 13 - a matéria propiciou uma visão integral do paciente; 14 - são necessárias aulas como estas durante todo curso de medicina)

\begin{tabular}{|c|c|c|c|c|c|c|c|}
\hline \multirow[b]{4}{*}{ Questão } & \multicolumn{6}{|c|}{ Respostas } & \multirow[t]{3}{*}{ pvalor } \\
\hline & \multicolumn{3}{|c|}{ sexo masculino } & \multicolumn{3}{|c|}{ sexo feminino } & \\
\hline & D & 1 & C & D & 1 & C & \\
\hline & $N(\%)$ & $N(\%)$ & $N(\%)$ & $N(\%)$ & $N(\%)$ & $N(\%)$ & \\
\hline 1 & $1(2,1)$ & $4(8,5)$ & $42(89,4)$ & $5(6,5)$ & $4(5,2)$ & $68(88,3)$ & 0,438 \\
\hline 2 & $1(2,1)$ & $5(10,6)$ & $41(87,2)$ & $6(7,8)$ & $11(14,3)$ & $60(77,9)$ & 0,321 \\
\hline 3 & $0(0)$ & $3(6,4)$ & $44(93,6)$ & $2(2,6)$ & $6(7,8)$ & $69(89,6)$ & 0,509 \\
\hline 5 & $3(6,4)$ & $13(27,7)$ & $31(66)$ & $10(13)$ & $31(40,3$ & $36(46,8)$ & 0,105 \\
\hline 6 & $O(0)$ & $1(2,1)$ & $46(97,9)$ & $0(0)$ & $O(0)$ & $77(100)$ & 0,199 \\
\hline 7 & $5(10,6)$ & $10(21,3)$ & $32(68,1)$ & $10(13)$ & $17(22,1)$ & $50(64,9)$ & 0,911 \\
\hline 8 & $5(10,6)$ & $7(14,9)$ & $35(74,5)$ & $5(6,5)$ & $19(24,7)$ & $52(67,5)$ & 0,429 \\
\hline 9 & $5(10,6)$ & $1(2,1)$ & $41(87,2)$ & $4(5,2)$ & $1(1,3)$ & $72(93,5)$ & 0,486 \\
\hline 10 & $0(0)$ & $0(0)$ & $47(100)$ & $2(2,6)$ & $1(1,3)$ & $74(93,5)$ & 0,391 \\
\hline 11 & $O(0)$ & $2(4,3)$ & $45(95,7)$ & $2(2,6)$ & $5(6,5)$ & $70(90,9)$ & 0,460 \\
\hline 13 & $3(6,4)$ & $2(4,3)$ & $42(89,4)$ & $4(5,2)$ & $4(5,2)$ & $69(89,6)$ & 0,939 \\
\hline 14 & $3(6,4)$ & $3(6,4)$ & $41(87,2)$ & $8(10,4)$ & $3(3,9)$ & $66(85,7)$ & 0,635 \\
\hline
\end{tabular}

Figura 8. Frequência das respostas a questão 4 de acordo com o sexo. $p$ valor $=0,272$. ( $N$, Não me ajudou em nada; $A F$, me ajudou de alguma forma;

$S$, me ajudou de maneira significativa; $M S$, me ajudou de maneira muito significativa)

12. Mudança na maneira de enxergar a medicina?

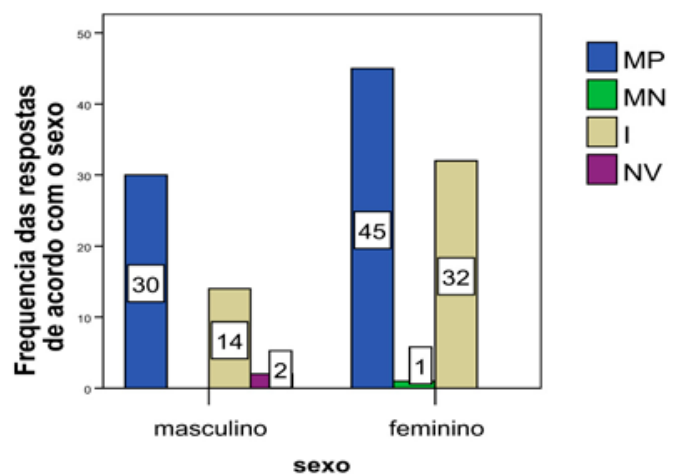

\section{Discussão}

O ensino médico atual tenta avançar do o antigo modelo de ensino biomédico, centrado na doença, em um modelo biopsicossocial. A perspectiva que tem como referência o modelo biopsicossocial tem-se afirmado progressivamente, proporcionando uma visão integral do ser e do adoecer que compreende as dimensões física, psicológica e social. ${ }^{10: 64}$

O modo como formar o médico cuidador, com visão holística do paciente, tem levado os responsáveis pelo ensino médico a perseguir novas técnicas didá-
Figura 9. Frequência das respostas a questão 12 de acordo com o sexo. P valor $=0,163$. (MP,mudança positiva; $M N$, maneira negativa;l, indiferente; NV, a matéria me fez ver que medicina não é minha vocação)

12. Mudança na maneira de enxergar a medicina?

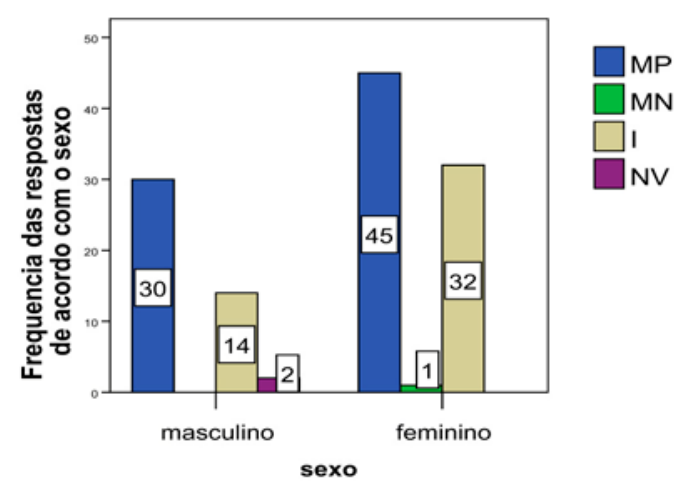

ticas para o ensinamento das humanidades durante a graduação. 11:14,12

O presente estudo mostra que a maioria dos alunos que passaram pela matéria Psicodinâmica da Clínica Médica, na Escola Bahiana de Medicina e Saúde Pública, conseguiram trabalhar os temas propostos de forma positiva e expressam a necessidade de mais espaços para abordar tais temas durante todo curso.

As respostas às perguntas 1,2 e 3 do questionário, que abordam aspectos referentes a relação médi- 
co-paciente, mostram que esse tema foi bem trabalhado e resultou na tomada de consciência do alunos para a importância deste elemento dentro da prática médica. Houve significância estatística quando comparado o ano de matrícula com as respostas à questão 3 ainda assim, a maioria dos alunos dos 3 anos analisados concordaram que passaram a prestar mais atenção ao aspecto terapêutico que pode ter a relação médico-paciente.

A prática desse tema objetivou que os alunos entendessem que apesar de todo avanço tecnológico, a relação interpessoal sempre terá lugar de destaque dentro da medicina. A prática clínica está para além das evidências anátomo-patológicas na medida em que, a singularidade da expressão das doenças por um corpo biológico, cujo "dono" também se expressa e, ao se expressar, também o expressa e o transforma num corpo simbólico, está a solicitar do médico observação, decodificação e interpretação. ${ }^{138-9}$

A importância do ensino da relação médico-paciente é destacada pela Mestre Rita Franco,quando diz: Compreender as vicissitudes pelas quais passam os nossos pacientes é uma ferramenta importante para - entendimento de seus males. $O$ ser que adoece não o faz isolado de sua realidade, mas, sim, inserido em sua historicidade. Compreender o ser humano em sua plenitude abre caminho para uma relação médico-paciente efetiva e possibilita o entendimento do adoecer. ${ }^{14: 40}$

O tema "a morte e o morrer" é contemplado em um dos encontros da matéria, e de acordo com as respostas do questionário a abordagem do tema ajudou a maioria dos alunos a entender melhor a morte e o morrer. Ainda assim, 12,1\% de todos alunos avaliados responderam que essa aula não os ajudou em nada quanto a esse tema. Por ser um tema muito polêmico e ser muito influenciado por questões pessoais e religiosas, é esperado que nem todos os alunos concordem com a maneira da abordagem que foi feita.

De acordo com entrevista dada pelo professor Luiz Queiroz, a morte foi abordada como algo natural, resultado do próprio processo evolutivo, independente de sua forma. Um estudo revela que muitos alunos e professores de medicina nunca participaram de debates ou seminários sobre morte, talvez pela ausência de contato com pacientes terminais. ${ }^{15: 24}$ É preciso porém, estar preparado para lidar com estas situações, que a qualquer momento podem se apresentar para quem lida com a medicina.

A matéria aborda o tema vocação médica, expondo situações do contexto que faz alguém escolher ser médico. Procura elucidar os interesses reais, mais profundos de cada um, ao tomar essa escolha. $O$ que thes motivou a escolher a medicina? Vocação? O amor pelo outro? O dinheiro? Influência familiar? O presente questionário revelou que muitos alunos $35,5 \%$ se posicionam de forma indiferente quando questionados se a matéria os fez refletir sobre sua escolha por medicina, tendo os alunos do $6^{\circ}$ ano como os principais responsáveis por esse número. $40 \%$ deles se mostraram indiferentes. Esse dado pode refletir dois pontos: os alunos participam dessa matéria após cursarem metade do curso de medicina, período suficiente para a tomada de consciência a respeito de sua escolha ou a matéria não abordou o assunto de maneira adequada, a ponto de chamar a atenção dos alunos. Apesar disso, é importante notar que na questão 12, 2 alunos responderam que a matéria os fez ver que medicina não é a vocação deles. Isso pode sugerir que esses alunos terão um vínculo mais superficial com sua profissão, comparados com aqueles que têm vocação pela medicina. ${ }^{16: 32}$

A humanização também é parte integrante nas discussões da Psicodinâmica. As perguntas 6 e 7 elucidaram esse tema. Foi observado o maior número de concordância nas respostas dadas quando se questionou se é preciso primeiro humanizar-se para atender com humanidade. Também foi constatado que a maioria dos alunos concordaram que a matéria mudou sua visão sobre a humanização, principalmente os alunos do $6^{\circ}$ ano, revelando que muitos alunos não conheciam o verdadeiro sentido da palavra humanização, ressaltando a necessidade de trabalhar esse tema.

Apesar de ser ainda muito difícil ter uma definição objetiva do que seja humanização, nas palavras em entrevista com o professor Luiz Queiroz, a visão passada durante o curso é que humanizar-se é entrar em contato com sua própria sombra, visando preparar-se para lidar consigo mesmo e com 
- outro. Quanto mais o profissional reflete sobre a sua realidade subjetiva, mais se torna consciente e capaz de intervir na realidade objetiva e, dessa forma, transformá-la. 17:428

As questões 8 e 9, norteiam a problemática da real função do médico: cuidar ou curar? Durante a vida profissional a cura de muitos pacientes não será possível mas, isso não quer dizer que a função do médico deixe de existir. A matéria apresenta a importância do cuidado, seja ele curativo ou paliativo, mostrando onde deve se basear o verdadeiro sentido da medicina. $O$ acadêmico em sua formação deve compreender o sentido de saber conduzir os pacientes e seus familiares para $\circ$ entendimento e aceitação de uma doença terminal, que é indiferente à nossa vontade, para não abandonar o paciente por não saber como tratá-lo paliativamente e por não ter desenvolvido habilidades no cuidado com o paciente terminal. ${ }^{18}$

Os alunos do $6^{\circ}$ ano foram os que mais concordaram, quando perguntados se o compromisso do médico é de cuidar e não de curar, revelando que possa existir um amadurecimento associado a uma maior prática da medicina, já que foram os que mais apresentaram respostas concordantes, não só nessa questão.

As respostas às questões 10 a 14 revelam que a matéria vem conseguindo atingir seu objetivo de propiciar uma visão integral do paciente e que os conhecimentos adquiridos têm aplicabilidade na vida acadêmica e profissional, segundo as respostas dadas ao questionário. Pode-se dizer que a matéria não foi apenas um momento de discussão, e sim, de reflexão e interiorização dos assuntos abordados. Os alunos entenderam que o aspecto humanístico na formação médica é tão necessário quanto o aspecto técnico. $O$ atendimento médico exige o conhecimento técnico especial, ao tratar o homem doente, não se descurando, porém, dos princípios e dos preceitos de respeito à dignidade humana, tomando a si o paciente não somente considerando seu corpo enfermo, mas sua integral constituição como ser humano. ${ }^{19: 14}$

A maioria dos alunos revelou que a matéria teve um impacto positivo. A maioria dos alunos também compartilham da opinião que matérias como esta devem ser disponibilizadas durante todo curso de medicina, mostrando o desejo de aprofundar os conhecimentos a respeito dos aspectos humanísticos ligados a medicina, visando a criação de bases para exercê-la em sua forma plena.

\section{Conclusão/Considerações finais}

- A Psicodinâmica da Clínica médica vem atingindo os objetivos propostos na medida em que:

- Contribui na formação de bases para que os alunos estabeleçam uma relação médico-paciente eficaz; Faz com que os alunos dêem mais atenção ao fatores pessoais, familiares e ambientais relacionados ao paciente;

- Chama atenção para o aspecto terapêutico que pode ter a relação médico-paciente;

- Faz os alunos refletirem sobre sua vocação por medicina;

- Modifica a interpretação do termo "humanização", revelando que para atender com humanidade é preciso primeiro trabalhar em si a humanização;

- Ajuda a diminuir a angústia e culpa dos alunos, frente a situações de doenças terminais ou mesmo a morte, mostrando que a função mais importante do médico é cuidar e não curar;

- Os alunos concordam que os temas abordados têm lugar na prática médica.

A Psicodinâmica da Clínica Médica tem uma grande aceitação e revela ter um impacto positivo na vida dos alunos.

Os alunos do $6^{\circ}$ ano apresentaram o maior nível de aceitação e conhecimento sobre a matéria, revelando que a prática clínica exerce alguma influência quando se fala de fundamentos humanísticos.

Foi observada diferença estatística, em relação ao ano de matrícula, nas respostas dadas apenas a uma questão, questão 5 , revelando que existe uma homogeneidade de opiniões entre aqueles que passaram pela matéria.

A análise estatística não mostrou significância quando comparados sexo e frequiência das respostas. 
Há necessidade do ensino de fundamentos humanísticos durante todo curso de medicina.

\section{Conflitos de interesses}

Nenhum conflito financeiro, legal ou político envolvendo terceiros (governo, empresas e fundações privadas, etc.) foi declarado para nenhum aspecto do trabalho submetido (incluindo mas não limitandose a subvenções e financiamentos, conselho consultivo, desenho de estudo, preparação de manuscrito, análise estatística, etc).

\section{Referências}

1. Conselho Federal de Medicina. A medicina e os atos médicos: Em defesa do direito da população à assitência médica digna e de qualidade [Internet]. 2003 [acessado em 2008 out. 08]. Disponível em: www.lava.med.br/SBACV/ ato_medico_pdf

2- Muccioli C, Campos MSQ, Dantas PEC, Goldchmit M, Bechara SJ, Costa VP, Matayoshil S. A humanização da medicina. Arq Bras Oftalmol. 2007;70(06):897. doi: $10.1590 /$ S0004-27492007000600001

3- Diniz DS. A "ciência das doenças" e a " arte de curar": trajetórias da medicina hipocrática [dissertação]. Rio de Janeiro: Universidade do Estado do Rio de Janeiro, Instituto de Medicina Social; 2006.

4- Pessini L. Humanização da dor e sofrimento humanos no contexto hospitalar. Bioética. 2002;10(2).

5- Cecin RB. Recursos humanos de saúde: desafios global e nacional. In: Seminário anual dos observatórios de recursos humanos de saúde nos processos de reforma setorial na região das Américas, 2004; Brasília.

6- Caprara A, Franco ALS. A relação paciente-médico: para uma humanização da prática médica. Cad Saúde Pública. 1999;15(3):647-654. doi: 10.1590/S0102$\underline{311 \times 1999000300023}$

7- Bittar OJNV. Médicos e Medicina. Rev do IDPC. 2002;IV(01)23-26.

8- Brasil. Ministério da Educação. Resolução $n^{\circ} 3$, de 20 de junho de 2014 . Institui Diretrizes Curriculares Nacionais do Curso de Graduação em Medicina e dá outras providências.

9- Branco RFGR, Azevedo AR, Sousa NKO, Siqueira PC, Pires RD, Paiva RF. Avaliação do processo de ensino/ aprendizagem da relação médico-paciente no curso de medicina da Universidade Federal de Goiás. Revista da UFG. 2005;7(2):59-61.
10- De Marco MA. Do Modelo Biomédico ao Modelo biopsicossocial: um projeto de educação permantente. Rev Bras Educ Med. 2006;30(1)60-72. doi: 10.1590/50100$\underline{55022006000100010}$

11 - Branco RFGR.O ensino na perspectiva dos grupos balint: um espaço de reflexão sobre o encontro do estudante de medicina com o seu paciente [dissertação]. Goiânia: Universidade Federal de Goiás. Faculdade de Educação; 2001.

12- Mota GM, Mota DMC, Machado MMT, Arrais RH, Oliveira CPV, Salgado MS et al. Ungraduate students view on the presence of clown-doctors at the University Hospital. Revista Brasileira em Promoção da Saúde. 2012;25(Supl 2): 25-32. doi:10.5020/2241

13- Souza ARND. Formação médica, racionalidade e experiência: o discurso médico e o ensino da clínica [dissertação]. Rio de Janeiro: Universidade Federal do Rio de Janeiro; 1998.

14- Branco RFGR. O Médico e a Perplexidade Frente ao $3^{\circ}$ Milênio: O Que Fazer? Rev UNIMED. 2000;XIII(78):40-41.

15- Vianna A, Picceli H. O estudante, o médico e o professor de medicina perante a morte e o pacienta terminal. Rev Ass Med Brasil. 1998;44(1):21-27. doi: 10.1590/S010442301998000100005

16- Millan, LR. A importância da vocação médica. Rev HospUniv. $2001 ; 11$ (1/2)30-33.

17- Backes DS, Lunardi Filho WD, Lunardi VL. A construção de um processo interdisciplinar de humanização à luz de Freire. Texto Contexto Enferm. 2005; 14(3):427-434. doi: 10.1590/ $\underline{\text { S0104-07072005000300015 }}$

18- Buffon VR. O estudante de medicina diante da finitude do homem. Prat Hosp. 2006;8(45):159-161.

19- Ristow AM. A formação humanística do médico na sociedade do século XXI: uma análise curricular [dissertação]. Curitiba: Universidade Federal do Paraná; 2007. 